\title{
Drug Utilization Evaluation of Anti-diabetics in Type 2 Diabetes Mellitus Patients with or without Comorbidities in a Tertiary Care Teaching Hospital
}

\author{
Rini Ponnachan, Brijith Babu, Sukanya Yesodhar, Santhosh Utangi*
}

Department of Pharmacy Practice, SCS College of Pharmacy, Harapanahalli, Karnataka, INDIA.

\begin{abstract}
Background: Evaluation of utilization pattern and prescribing trend of anti-diabetics is of paramount importance to promote rational drug use. Objectives: The primary objective of this research is to assess drug utilization evaluation of anti-diabetics in type 2 diabetes mellitus patients with or without comorbidities. Methods: A prospective observational study was carried out for six months in the inpatient medicine department of Chigateri District, Hospital Davanagere. Results: A total of 151 patients were enrolled, out of which $93(62 \%)$ patients were males and $58(38 \%)$ patients were females. Most of the patients belong to the age group of $51-60(29 \%)$ years, followed by $61-70(28 \%)$ years. The pattern of drug prescription in diabetes shows that insulin (52\%) was the most utilized monotherapy followed by metformin (47\%). Among dual therapy, $34(60 \%)$ patients were treated with the combination of metformin + glimepiride. A total of 8 patients were treated with triple therapy, out of which $4(50 \%)$
\end{abstract}

patients were prescribed a combination of metformin+glimepride+human actrapid. Conclusion: The prescribing trend was found to be monotherapy with insulin followed by dual therapy and triple therapy. The combination of biguanides and sulfonylureas was the most commonly prescribed antidiabetic regimen among dual therapy.

Key words: Utilization Pattern, Comorbid, Anti-diabetics, Prescribing Trend.

Correspondence

Dr. Santosh Uttangi,

Department of Pharmacy Practice, SCS College of Pharmacy, Harapanahalli583131, Karnataka, INDIA.

Email id: santoshuttangi05@gmail.com

DOI: 10.5530/jyp.2021.13.54

\section{INTRODUCTION}

"Diabetes Mellitus (DM) is a chronic metabolic disease characterized by elevated levels of blood glucose with disturbances in carbohydrates, fat and protein metabolism resulting from defects in insulin secretion, insulin action, or both." The escalation in the incidence of diabetes purses the trend of urbanization and changing lifestyle includes less physical activitiesand intake of energy-dense foods with poor nutritional value. ${ }^{2}$ As per World Health Organization (WHO), In the year 2000, there were around 31.7 cases of DM and it is thought to reach around 80 million by the year 2030.,4 Type $2 \mathrm{DM}$ can also have comorbid conditions like hypertension (HTN), dyslipidemia and chronic kidney disease (CKD). ${ }^{5,6}$ Diabetes-related complications can be prevented or flattened by adopting healthy lifestyle measures and optimal glycaemic management using the optimal therapeutic options, thus reducing the cost burden among the diabetics. The choice of anti-diabetic depends on the levels and target to be achieved for glycaemic levels, availability of drugs and cost of medicines. ${ }^{?}$

Drug utilization studies are basic yet crucial studies that allow us to compare the prescribed drug according to guidelines. Drug utilization studies can effectively detect inappropriate drug therapy after continuous monitoring of treatment regimens for a specific disease. ${ }^{8}$ DUE studies aim to promote rational use of a drug, prevent drug-related problems, and improve quality of life. Clinical pharmacists play an essential role in conducting the utilization studies by utilizing their knowledge of clinical pharmacy practice. ${ }^{9,10}$ With these needs, we tried to analyse the DUE pattern of anti-diabetic and assess how close they are to optimal care.

\section{MATERIALS AND METHODS}

A prospective observational study was conducted in the medicine department of Chigateri District Hospital, Davanagere, for six months after obtaining an institutional ethics committee clearance and permission from the hospital's medicine department. The study was carried out by considering the following inclusion and exclusion criteria. Patients of either gender above 18 years of age diagnosed with type 2 diabetes mellitus admitted to the general medicine of Chigateri hospital and prescribed with at least one anti-diabetic drug were included in the study. Patients diagnosed with type I and gestational diabetes or the patients who only received the treatment from the outpatient department and patients with insufficient data were excluded from the study. A suitably designed data collection form was developed and written informed consent was obtained prior to data collection. The data collection form contains all relevant data and those are collected from patient profile forms during ward rounds. The collected data were categorized and analyzed by using MS Excel. The extracted results were presented in graphs and tables.

\section{RESULTS}

Distribution of patients based on their gender and age

A total of one hundred fifty-one patients were enrolled in the study. Out of them, $n=93(62 \%)$ were male and the remaining $n=58$ (38\%) were females. The results also revealed that a maximum number of patients were in the age group of 51-60 years, $n=44$ (29\%) followed by $61-70$ years, $n=43(28 \%)$. Only a few diabetic patients belong to the age group of

This is an open access article distributed under the terms of the Creative Commons Attribution-NonCommercial-ShareAlike 4.0 License, which allows others to remix, tweak, and build upon the work non-commercially, as long as the author is credited and the new creations are licensed under the identical terms. 
Table 1: Age-wise distribution of Patients.

\begin{tabular}{cccc}
\hline Age group & $\begin{array}{c}\text { No of male } \\
\text { patients }\end{array}$ & $\begin{array}{c}\text { No of female } \\
\text { patients }\end{array}$ & Total (\%) \\
\hline 21-30 years & 3 & 1 & $4(3 \%)$ \\
31-40 years & 13 & 5 & $18(12 \%)$ \\
$41-50$ years & 14 & 12 & $26(17 \%)$ \\
$51-60$ years & 26 & 18 & $44(29 \%)$ \\
$61-70$ years & 26 & 17 & $43(28 \%)$ \\
$71-80$ years & 7 & 5 & $12(8 \%)$ \\
$81-90$ years & 4 & 0 & $4(3 \%)$ \\
Total & $\mathbf{9 3}$ & $\mathbf{5 8}$ & $\mathbf{1 5 1}(\mathbf{1 0 0} \%)$ \\
\hline
\end{tabular}

Table 2: Distribution of comorbidities.

\begin{tabular}{ccc}
\hline Co-morbidities & $\begin{array}{c}\text { Number of } \\
\text { patients }\end{array}$ & Percentage (\%) \\
\hline Hypertension & 56 & $38 \%$ \\
Cardiovascular disease & 34 & $23 \%$ \\
Lower respiratory tract infections & 21 & $14 \%$ \\
Chronic kidney disease & 11 & $8 \%$ \\
Diabetic ketoacidosis & 7 & $5 \%$ \\
Urinary tract infections & 7 & $5 \%$ \\
Alcoholic liver disease & 4 & $3 \%$ \\
Diabetic foot & 3 & $2 \%$ \\
Hypothyroidism & 3 & $2 \%$ \\
Total & $\mathbf{1 4 6}$ & $\mathbf{1 0 0} \%$ \\
\hline
\end{tabular}

21-30 and 81-90 years, $n=4$ (3\%) each. The detailed age-wise distribution is shown in Table 1 .

\section{Distribution of patients based on their comorbidities}

Among the 151 patients, 56 (38\%) patients had hypertension, followed by cardiovascular disease in 34 (23\%) patients. Complete data regarding the distribution of comorbidities is depicted in Table 2.

\section{Drug utilization evaluation of hypoglycaemic agents}

Among all the patients, $n=86$ (57\%) were treated with monotherapy, followed by $n=57$ (38\%) treated with dual therapy and only $n=8(5 \%)$ were on triple therapy. Out of 86 patients who underwent monotherapy, $n=45(52 \%)$ patients were prescribed insulin, $n=40$ (47\%) patients were prescribed with biguanides, followed by sulfonylureas prescription in $n=1$ (1\%) patient. The results on dual therapy revealed that, out of 57 prescriptions, $n=34(60 \%)$ patients were prescribed with metformin+glimepride followed by a combination of human actrapid+humanmixtard in $n=12(21 \%)$ patients. However, only one patient was prescribed metformin+humanactrapid. Similarly, in triple therapy, out of 8 patients, $n=4(50 \%)$ patients have prescribed a combination of metformin+glimepride+humanactrapid. The combinations of metformin+glimepride+human mixtard (25\%) and metformin + human mixtard+ human actrapid (13\%) were prescribed only in each patient.
Table 3: Utilization pattern in comorbidity drugs.

\begin{tabular}{ccc}
\hline Class of drugs & $\begin{array}{c}\text { Number of drugs prescribed } \\
(\mathrm{n})\end{array}$ & Percentage (\%) \\
\hline $\begin{array}{c}\text { PPI/H } \mathrm{H}_{2} \mathrm{~A} \\
\text { (gastroprotective) }\end{array}$ & 44 & $20 \%$ \\
Antibiotics & 36 & $16 \%$ \\
Anticoagulants & 32 & $15 \%$ \\
Diuretics & 24 & $11 \%$ \\
Calcium channel blockers & 20 & $9 \%$ \\
Corticosteroids & 16 & $7 \%$ \\
ARB \& ACE inhibitors & 15 & $7 \%$ \\
Beta blockers & 11 & $5 \%$ \\
HMG- CoA reductase & 10 & $5 \%$ \\
inhibitor & 10 & $5 \%$ \\
Leukotriene receptor & & $\mathbf{1 0 0 \%}$ \\
antagonists & $\mathbf{2 1 8}$ & \\
Total & & $5 \%$
\end{tabular}

Note: Proton Pump Inhibitor, H2RA: Histamine 2 Receptor Blocker, ARB: Angiotensin Receptor Blockers, ACE: Angiotensin-converting Enzymes, HMG- CoA: $\beta$-Hydroxy $\beta$-methylglutaryl-CoA.

\section{Drug utilization pattern of drugs used to treat comorbidities}

A total of $n=218$ drugs were prescribed to treat the associated comorbidities. Among these agents, gastroprotective agents were prescribed $n=44(20 \%)$ frequently, followed by antibiotics $n=36(16 \%)$, whereas statins and leukotriene receptor antagonists were the least prescribed agents $n=10$ (5\%). The details are referenced in Table 3.

\section{DISCUSSION}

Diabetes, a chronic metabolic disorder, affects a large spectrum of the population globally with the increasing trend of morbidity and mortality and is the seventh leading cause of death worldwide. In the present study, the prevalence of diabetes mellitus was more in males (62\%) belongs to the age group of 51-60 (29\%) years, which is in agreement with the various studies conducted in Saudia Arabia and India by Abbasi M Y et al. ${ }^{11}$ and Haghighatpanah $\mathrm{M}$ et al. ${ }^{12}$ respectively indicating that the risk of diabetes mellitus increases after the age of 50 years. In our study, we observed more patients who are either obese or overweight. The study also revealed that hypertension (38\%) was the most predominant comorbidity followed by cardiovascular disease (23\%), which is comparable with a similar previous study conducted in Uttarakhand by Yogesh $\mathrm{J}$ et $a .^{2}$ with regard to the comorbidity in patients with diabetes. The association between diabetes and hypertension is clinically important because it amplifies the risk of diabetic complications.

In this study, anti-diabetics were prescribed monotherapy, dual therapy and triple therapy. A significant rise was observed in the monotherapy (57\%) prescribing trend, whereas dual therapy and triple therapy accounted for $38 \%$ and $5 \%$, respectively. This pattern of anti-diabetic drug prescription is due to disease severity along with other comorbidities. The most preferred drug of choice for the treatment of type 2 diabetes is monotherapy. According to this study finding, insulin (52\%) is the most utilized drug among monotherapy, followed by metformin (47\%) and glimepiride (1\%). This result is consistent with the results of studies conducted in Karnataka by Arun J et al. ${ }^{1}$ and Abdi S A H et al. ${ }^{3}$ This report contrasts the report of studies done in India by Maiti $\mathrm{T}$ et al. ${ }^{13}$ where they reported that during hospital stay of the patient metformin 
Ponnachan, et al.: Drug Utilization Evaluation of Anti-diabetics in Type 2 Diabetes Mellitus

was the most commonly prescribed anti-diabetic agent among monotherapy. Increased utilization of human mixtard and human actrapid has greatly increased in patients due to the presence of comorbid conditions or resistance to oral hypoglycemic agents. ${ }^{1}$ However, it is noteworthy that metformin is predominantly prescribed in the category of biguanides. Beneficial effects of metformin include delayed progression of the disease, improve lipid profile, weight reduction, cost and low incidence of adverse effects, reduce insulin resistance thus slightly less incidence of hypoglycemia, prevents microvascular and macrovascular complication and can be associated with any other anti-diabetic agent. ${ }^{1-3}$

Among fixed drug combinations, our study found that the combination of metformin and glimepiride was the commonly prescribed regimen (34 patients). This finding is in line with that of studies conducted in Karnataka by Jagadeesh $\mathrm{K}$ et al. ${ }^{5} \mathrm{It}$ is noticeable that glimepiride remains the best choice for combination with metformin due to its maximum potency to lower blood glucose level. Another striking advantage of glimepiride was its long half-life, thus better patient compliance and its complete metabolism to inactive metabolites eliminating the risk of hypoglycemia. In the current study area setting, the combination of metformin+glimepride+insulin (50\%), metformin+glimepride+pioglita zone $(25 \%)$, were prescribed as triple therapy, which is similar to a study conducted in Karnataka by Arun J et al. ${ }^{1}$

This study also revealed that the most commonly co-prescribed nondiabetic drugs were anti-hypertensive due to the predominance of hypertension as the most common comorbidity in the study. These findings are congruent with other previous studies done in Maharashtra by Patil VN et al. ${ }^{14}$

\section{CONCLUSION}

In our study, males outnumber females suggesting males are more prone to be affected by diabetes. A relative preponderance of diabetes was observed in males belongs to the age group of 51-60 years. Quite a lot of diabetic patients had hypertension, followed by cardiovascular disease as comorbidity. The prescribing trend was found to be monotherapy followed by dual therapy and triple therapy. Insulin was the most commonly prescribed drug among monotherapy, followed by metformin. The combination of biguanides and sulfonylureas was the most commonly prescribed antidiabetics regimen among dual therapy. Glimepiride has emerged as the front liner among sulfonylureas. Anti-hypertensives were the most commonly co-prescribed non-diabetic drugs due to the predominance of hypertension in the majority of the sample population. Anti-diabetic drug utilization patterns should be based on disease severity and associated comorbid condition.

\section{ACKNOWLEDGEMENT}

We authors want to thank the staff of SCS College of Pharmacy, Harapanahalli, for their support during the study. We also wish to express our heartfelt thanks to Dr. Barma Naga Raju for his suggestions, inspiration, and for his unflinching support throughout the work.

\section{CONFLICT OF INTEREST}

The authors declare no conflict of interest.

\section{ABBREVIATIONS}

DM: Diabetes mellitus; WHO: World Health Organization; CKD: Chronic Kidney Disease; HTN: Hypertension; DUE: Drug Utilization Evaluation; MS: Microsoft; PPI: Proton Pump Inhibitor; $\mathbf{H}_{2} \mathbf{R A}$ : Histamine 2 Receptor Blocker; CCB: Calcium Channel Blocker; ACE: Angiotensin-converting Enzymes; ARB: Angiotensin Receptor Blockers.

\section{REFERENCES}

1. Arun J, Chand S, Nagaraju B, Acharya M, Anusha R. A study to assess drug utilization on type $2 \mathrm{DM}$ patients with or without complications in general ward of tertiary care teaching hospital at Vijayanagar Institute of Medical Sciences, Ballari, Karnataka. Indo Am J Pharm Res. 2018;8(3):394-402.

2. Verma S, JoshiY, Singh A. Drug utilization evaluation of anti-diabetic medication through prescription monitoring. Asian J Pharm Res Dev. 2019;7(3):75-7. doi: 10.22270/ajprd.v7i3.537.

3. Abdi SAH, Churi S, Kumar YSR. Study of drug utilization pattern of antihyperglycemic agents in a South Indian tertiary care teaching hospital. Indian J Pharmacol. 2012;44(2):210-14. doi: 10.4103/0253-7613.93850, PMID 22529477.

4. Kurian SP, Nongrum G, Thomas AM, Sonkusare SS. A study on occurrence of gestational diabetes mellitus and its clinical management. Plant Arch. 2020;20(01):1823-7.

5. Jagadeesh K, Kauser MM, Afreen A, Rekha L. Drug utilization evaluation in diabetic patients in a tertiary care teaching hospital: A prospective observational study. J Drug Deliv Ther. 2014;4(5):147-51.

6. James M, Varghese TP, Sharma R, Chand S. Association between metabolic syndrome and diabetes mellitus according to international diabetic federation and national cholesterol education program adult treatment panel III criteria: a cross-sectional study. J Diabetes Metab Disord. 2020;19(1):437-43. doi: 10.1007/s40200-020-00523-2, PMID 32550195.

7. Sunny S, Shastry CS, Mateti UV, Chand S, Sharma R. Pharmacoeconomic evaluation on treatment of diabetic patients in a charitable hospital. Indian $\mathrm{J}$ Pharm Sci. 2020;82(3):532-7. doi: 10.36468/pharmaceutical-sciences.678.

8. Al-Jabri MM, Shastry CS, Chand S. Assessment of drug utilization pattern in chronic kidney disease patients in a tertiary care hospital based on who core drug use indicators. JGPT. 2019;11(9):1-9.

9. Sah SK, R S, Ramesh M, Chand S. Impact of pharmacist care in the management of autoimmune disorders: A systematic review of randomized control trials and non-randomized studies. Res Social Adm Pharm. 2020. doi: 10.1016/j. sapharm.2020.12.005, PMID 33423904

10. Voora L, Sah SK, Bhandari R, Shastry CS, Chand S, Rawal KB et al. Doctor of pharmacy: boon for healthcare system. Drug Invent Today. 2020;14(1):153-8.

11. Abbasi MY, Avez A, Alshammari M. A prospective study on prescribing patterns of anti-diabetic drugs. WJPPS. 2014;3(5):45-57.

12. Haghighatpanah M, Thunga G, Jha A, Mallayasamy S. Study on prescribing pattern of anti-diabetes patients with complication in South Indian teaching hospital. Asian J Pharm Clin Res. 2016;9(1):194-7.

13. Mandal S, Maiti T, Das AK, Das A, Mandal A, Sarkar BS, et al. A study on drug utilization pattern in patients of type 2 diabetes mellitus attending referral diabetic clinic at a tertiary care teaching hospital in Rural Bengal. Int J Basic Clin Pharmacol. 2016;5(4):1647-54.

14. Patel B, Oza B, Patel KP, Malhotra SD, Patel VJ. Pattern of antidiabetic drugs use in type-2 diabetic patients in a medicine outpatient clinic of a tertiary care teaching hospital. Int J Basic Clin Pharmacol. 2013;2(4):485-91. doi: 10.5455/2319-2003. ijbcp20130826. 